\title{
ACTOS ULTRA VIRES DE LA UNIÓN EUROPEA Y DERECHO A LA PARTICIPACIÓN POLÍTICA: LA DECISIÓN DEL TRIBUNAL CONSTITUCIONAL ALEMÁN SOBRE EL PROGRAMA DE ADQUISICIÓN DE DEUDA PÚBLICA DEL BANCO CENTRAL EUROPEO
}

LEONARDO ÁLVAREZ ÁLVAREZ

Profesor Titular (A) de Derecho Constitucional

Universidad de Oviedo

SUMARIO

I. La decisión del Banco Central Europeo sobre la adquisición de deuda pública en el contexto de la jurisprudencia del Tribunal Constitucional Federal.

II. El programa de adquisición de deuda pública y la doctrina ultra vires del Tribunal Constitucional Federal alemán.

III. El programa de adquisición de deuda pública del Banco Central Europeo y el principio de responsabilidad por la integración.

IV. El debate planteado en los votos particulares. Actos ultra vires, identidad constitucional y división de poderes.

\section{LA DECISIÓN DEL BANCO CENTRAL EUROPEO SOBRE} LA ADQUISICIÓN DE DEUDA PÚBLICA EN EL CONTEXTO DE LA JURISPRUDENCIA DEL TRIBUNAL CONSTITUCIONAL FEDERAL ALEMÁN

a) El programa de adquisición de deuda pública y la contraposición entre dos visiones sobre el proceso de la UE. Cada vez que se espera una decisión del Tribunal Constitucional Federal —en adelante, TCF — sobre el proceso de integración europea, se 
respira una cierta preocupación. Una preocupación que suele expresar, de ordinario, la tensión entre dos formas distintas de entender el proceso de integración europea, perceptible tanto en el debate académico como en los agentes políticos. La que ha puesto su énfasis, primero, en el reforzamiento de la unidad político-económica que engloba a los diversos Estados, como presupuesto del mejor desarrollo de la estatalidad propia. Y la que, por el contrario, se ha centrado ante todo en la defensa de la estatalidad como presupuesto para una unión más fuerte.

La decisión del Banco Central Europeo —en adelante BCE_, de 06.09.2012, destinada a garantizar la irreversibilidad del euro y la consolidación de la unión monetaria como presupuesto necesario para el eficaz desarrollo de las políticas económicas de los Estados, y los recursos interpuestos frente a aquella ante el TCF, que esgrimen que las medidas de la unión monetaria se ha adoptado a costa de los principios fundamentales que predeterminan el núcleo de la soberanía del Estado alemán, expresan la síntesis entre aquellas antitéticas posiciones. El propio texto de la decisión del TCF, de 14.01.2014, refleja tales perspectivas en la voluntad mayoritaria de la Sala y en los votos particulares que se interpusieron a la misma.

La decisión del BCE, enmarcada en un contexto de grave crisis económica, habilitaba la posibilidad de que dicha institución adquiriera de manera ilimitada deuda pública de determinados Estados (selectividad) en el mercado secundario con vencimiento de 1 a 3 años. La decisión del BCE, destinada a abaratar las condiciones de financiación de los Estados, se hacía depender (condicionalidad) de que los Estados beneficiarios se adhirieran el programa de reformas establecidos en el Mecanismo Europeo de Estabilidad o en el Programa de Facilidad Europea (paralelismo). Contra la decisión del BCE se interpusieron ante el TCF seis recursos de amparo y un conflicto entre órganos constitucionales dirigidos a) contra la participación del Banco Central alemán en la ejecución de la decisión del BCE y b) contra la inacción del Gobierno y del Parlamento federal frente a un acto de derecho derivado que los recurrentes entendían contrario a la Ley Fundamental.

b) El encaje de la decisión sobre el programa de adquisición de deuda pública en la jurisprudencia sobre la competencia de control del TCF. La jurisprudencia del TCF sobre el proceso de integración europea ha sido siempre favorable a la segunda de las posiciones arriba descritas: la que se propone la defensa de la estatalidad como presupuesto necesario para el desarrollo de la UE. También esta perspectiva es la que se encuentra presente en la decisión sobre el programa de adquisición de deuda pública del BCE. Ello es, en realidad, el resultado de una concreta teoría del Estado y de la Constitución asumida por el TCF que, sin embargo, los votos particulares entienden abandonada en la decisión ahora comentada. En un discurso tan coherente como criticado, y vinculado cada vez más los presupuestos de la teoría tradicional del Estado (BVerfGE. 123, 267-Lissabon-), el TCF ha atribuido a la UE la naturaleza jurídica de a) unión de Estados soberanos, b) carentes de una norma formalmente constitucional y c) cuyos actos se encuentran, por lo tanto, jerárquicamente infraordenados a la Constitución (véase ya la BVerfGE 22, $293-E W G$ Verordnungen-). 
Con todo, esta jurisprudencia no ha sido precisa en todos los casos en lo que se refiere a la facultad de control del derecho derivado de la UE (cfr. BVerfGE. 89, 155 - Maastricht, 102, 147-Bananenmarktordnung). Justamente en este debate se encuadra la decisión del TCF sobre el programa de adquisición de deuda pública del BCE, que viene a abrir una nueva vía para el control del TCF. La jurisprudencia del TCF había dejado claro que de la supremacía jerárquica de la Ley Fundamental frente al derecho comunitario deriva su facultad para el control sobre la aplicabilidad - que no la validez- de los actos de derecho derivado dentro de Estado alemán (BVerfGE. Eurokontrol I, 58, 1 (30 y 31); Kloppenburg 75, 223 (235 y 242). Y también que tal control sobre la aplicabilidad no podía tener por objeto, sin más, cualquier «acto infractor» de la Ley Fundamental, como los denominó en la Sentencia Maastricht (BVerfGE. 89, 155, 91-106).

La facultad de control del derecho comunitario derivado por parte del TCF se limitaba solo a los actos que, desde la Sentencia Lisboa de 2009, denominó ultra vires, por implicar una infracción especialmente cualificada de la Ley Fundamental (BVerfGE. 123, 267, p. 240). El ámbito de control jurisdiccional del TCF se limitó, en consecuencia, a lo que denominó un control de identidad de la soberanía del Estado alemán [BVerfGEE. 75, 223 (235, 242); 89, 155 (188); 113, 273 -Europäischer Haftbefehl- (296); 123, 267 (353 y 354); 126, 286 -Ultra vires kontrolle-Mangoldt - (302)]. Un control de identidad constitucional de carácter subsidiario que es lo que permite distinguirlo y darle un sentido propio respecto de la facultad de control sobre la validez y la aplicabilidad del derecho comunitario atribuida primariamente al TJUE (art. 19,1 TUE). Los diferentes recursos interpuestos contra la decisión del BCE sobre el programa de adquisición de deuda de los Estados cuestionan justamente eso: que más allá de tratarse de un acto meramente infractor de las competencias y de las normas constitucionales del Estado alemán, constituía un acto ultra vires vulnerador de los principios que expresan la identidad de la Ley Fundamental.

En el contexto de estas consideraciones, la decisión del TCF sobre el programa de compras de deuda pública del BCE generó gran expectación. Tras la Sentencia Lisboa de 2009, en la que, como se vio, circunscribió su competencia de control sobre la aplicación del derecho comunitario a los actos ultra vires, sólo la Sentencia Mangoldt (BVerfGE. 126, 286), de 2010, había tenido la ocasión de pronunciarse sobre la aplicabilidad en el Estado alemán de un acto de derecho comunitario derivado. Sin embargo, en este caso, el TCF renunció finalmente a la realización de dicho control, al negar que el acto impugnado, en particular una decisión del TJUE, tuviese la consideración de acto ultra vires. Por eso se esperaba con gran interés la decisión del TCF, finalmente pronunciada el 14.01.2014, sobre el programa de adquisición de deuda pública del BCE, toda vez que suponía una nueva oportunidad para poder verificar la extensión y la intensidad del control sobre el derecho comunitario. Y no sólo ello, también poder determinar a través de qué vías procesales cabe impugnar tales actos. 
La decisión del TCF sobre el programa del BCE de adquisición de deuda pública concluye con el planteamiento de una cuestión prejudicial ante el TJUE, a fin de que se pronuncie sobre la supuesta extralimitación del BCE de las competencias atribuidas por los tratados constitutivos. Sin embargo, la aludida decisión del TCF no se limita a remitir la cuestión prejudicial al TJUE, suspendiendo el procedimiento. El TCF entra a conocer directamente el fondo del asunto, afirmando que, a salvo de que lo que determine el TJUE, la decisión del BCE puede considerarse, como entienden los recurrentes, un acto ultra vires contrario a los principios fundamentales de la Ley Fundamental. De este modo, el TCF activa su facultad de control subsidiario sobre la aplicabilidad de la decisión del BCE, en el caso de que el pronunciamiento del TJUE, o no la invalide o no reconduzca interpretativamente su contenido a las competencias del BCE previstas en los tratados constitutivos. A esto último es a lo que le insta el TCF por los motivos que seguidamente se expondrán.

\section{EL PROGRAMA DE ADQUISICIÓN DE DEUDA PÚBLICA Y LA DOCTRINA ULTRA VIRES DEL TRIBUNAL CONSTITUCIONAL FEDERAL ALEMÁN}

a) La doctrina ultra vires en la jurisprudencia del TCF. La jurisprudencia del TCF reconoció, como ha quedado dicho, que su competencia para el control subsidiario sobre la aplicabilidad del derecho comunitario derivado, previa decisión del TJUE, se limitaba a los actos ultra vires que implicasen una infracción cualificada de la Ley Fundamental. El TCF afirmó que el concepto de infracción constitucional cualificada se ponía en directa relación con la eficacia del contenido nuclear de los principios que definen la identidad de la Ley Fundamental: los que, sustraídos a cualquier reforma constitucional, se encuentran en el art. 79,3 [BVerfGE. Maastricht 89, 155 (171 y 172)]. La caracterización realizada de la decisión del BCE como acto «ultra vires» supone, por tanto, circunscribir su lesividad no solo la infracción directa de los tratados constitutivos y mediatamente a la norma constitucional (art. 23) que impide a los órganos de UE ejercer competencias no cedidas expresamente mediante ley por el Parlamento alemán [BVerfGEE. Eurokontrol I 58, 1 (37); 68, 1 -Atomwaffenstationierung-(98 y 99)].

El TCF califica a la decisión del BCE, a salvo de lo que determine el TJUE en respuesta a la cuestión prejudicial planteada, como un acto ultra vires por la satisfacción de las dos condiciones que definen tales actos [BVerfGE. 126, 286 - Ultra vires Kontrolle Mangoldt- (303 y 304)]: a) que suponga una «infracción competencial manifiesta» de los tratados constitutivos y b) que además genere un «desplazamiento estructural significativo» del orden competencial de los Estados miembros, lo que eleva al acto infractor, en la lógica del TCF, al carácter de infracción cualificada de los principios fundamentales plasmados en el art. 79,3 de la Ley Fundamental. A continuación se analizará qué argumentos aporta el TCF para entender que la decisión del BCE que habilita un programa de adquisición de deuda pública 
satisface aquellas dos condiciones. Unos argumentos que no convencen a los magistrados Lübbe-Wolff y Gerhardt, tal y como exponen en la redacción de sus votos particulares.

b) El programa de adquisición de deuda pública del BCE como infracción competencial manifiesta. El TCF entiende que la decisión del BCE constituye, en primer lugar, una infracción competencial manifiesta de las funciones reconocidas a la citada institución en los tratados constitutivos. Para el TCF de los tratados constitutivos de la UE cabe deducir la distinción formal entre lo que es la "política monetaria», que se reconocería propiamente al BCE, y la «política económica», que quedaría en manos de los diferentes Estados de la UE (Título VIII, y en los arts. 119, 2, 127,1 frase 2 del Tratado de Funcionamiento de la Unión Europea). Sobre la base de esta distinción, el TCF concluye que el programa de adquisición de deuda pública del BCE no constituiría el ejercicio de una política monetaria, sino que sería más bien la expresión de una política económica propia del BCE, que debe corresponder a los Estados. Para el TCF, del derecho originario solo cabe deducir, a lo sumo, la posibilidad de que el BCE pueda coordinar (art. $119 \mathrm{sec} .1$ TFUE) o apoyar las políticas económicas de los Estados miembros (art. 119 sec. 2, art. $127 \mathrm{sec} .1$ frase 2 TFUE), pero no abiertamente sustituirlas, algo que a juicio del TCF sucede en el caso del programa de adquisición de deuda pública del BCE. Desde luego, continúa el TCF, esta función coordinadora o de apoyo del BCE a las políticas de los Estados miembros sólo podría permitir, desde luego, decisiones generales, que se compadecen mal con el carácter selectivo del programa de adquisición de deuda pública aprobado por el BCE, dirigido solo a determinados Estados.

El razonamiento del TCF para acabar concluyendo la existencia de una «infracción competencial manifiesta» no sólo se apoya en la literalidad del Título VII TFUE, que se dedica a «la política económica y monetaria». Entre otras cosas porque, como el mismo TCF acaba reconociendo, el TFUE no define lo que sea la política económica. Por ello, el TCF se apoya también en la jurisprudencia del TJUE, que trató de delimitar el contenido de aquellas competencias. La Sentencia del TJUE, de 27.10.2012 — C-370/12, Pringle — había determinado que el contenido de la política monetaria del BCE abarca, entre otras facultades, la decisión sobre los tipos de interés para el área monetaria del euro y el lanzamiento de la moneda. Sin embargo, el TJUE dejó claro que excedía del contenido de tal competencia del BCE la concesión de asistencia financiera a los diferentes Estados, al amparo de lo previsto expresamente en el art. 123 TFUE que dispone: «Queda prohibida... la adquisición directa a los mismos de instrumentos de deuda por el Banco Central Europeo o los bancos centrales nacionales». El TCF, junto con el TJUE, entiende que este artículo 123 TFUE reserva a los Estados únicamente la determinación de sus condiciones de financiación o, en los términos empleados por el TCF, la competencia sobre su política económica. Eso es lo que, para el TCF, pretende también la decisión del BCE, como se deduce de su propia literalidad: «contribuir a una mejor financiación de ciertos Estados, permitiendo el abaratamiento de los tipos de interés que habrán de pagar por su deuda pública». 
Sin embargo, el TCF además de apoyarse en la literalidad del TFUE y en jurisprudencia del TJUE, recurre a otro argumento adicional para acabar concluyendo que la decisión del BCE supone una infracción manifiesta de las competencias de los Estados: el carácter condicionado del programa de adquisición de deuda pública. Como se puso de manifiesto con anterioridad, la decisión del BCE condicionaba la activación de las compras de deuda pública a corto plazo en el mercado secundario a que los Estados se comprometieran a asumir el programa de reformas previsto, bien en el Mecanismo Europeo de Estabilidad o en el Programa de Facilidad Europeo. Para el TCF, estos mecanismos, aprobados por los Estados miembros, constituyen una clara expresión del ejercicio de la competencia sobre política económica, estableciendo condiciones y límites de la financiación de los propios Estados. Para el TCF, el hecho de que el BCE haya condicionar justamente su programa de compras a la adhesión a tales mecanismos constituye una clara evidencia de que el BCE ha querido inmiscuirse en la competencia sobre la política económica. En conclusión, el TCF llega al convencimiento de que la decisión impugnada constituye, en primer lugar, una infracción competencial manifiesta de la política económica que corresponde a los Estados.

c) El programa de adquisición de deuda pública del BCE como desplazamiento estructural significativo de las competencias de los Estados. La decisión del TCF determina también, siempre a salvo de lo que determine el TJUE en respuesta a la cuestión prejudicial, que el programa de adquisición de deuda pública aprobado por el BCE implica un desplazamiento estructural significativo de las competencias de los Estados miembros, satisfaciendo así el segundo de los requisitos para que un acto de derecho comunitario derivado tenga la consideración de ultra vires y, consecuentemente, caiga en el ámbito del control del TCF. Según el TCF, la infracción competencial manifiesta del BCE es susceptible de poner en riesgo la eficacia del contenido nuclear de los principios fundamentales que en el art. 79,3 GG definen la soberanía del Estado alemán. Particularmente, la del principio democrático en el que, en último extremo, se condensan tales principios.

La jurisprudencia del TCF tuvo ya la ocasión de afirmar reiteradamente que forma parte inescindible del principio democrático la facultad del Parlamento federal para definir soberanamente la política presupuestaria-BVerfGEE. 70, 324-Hausbaltkontrolle der Nachrichtendienste — (355 y 356); 79, 311-Staatsverschuldung(329); 129, 124_EFS— (177)—. La decisión del BCE constituye una manifiesta intromisión en tal competencia, ya que, a juicio del TCF, el programa de adquisición de deuda pública puede conducir a una redistribución presupuestaria y a un ajuste financiero entre los Estados miembros que es susceptible de condicionar sus decisiones soberanas sobre la política económica. Como reconoció el TCF, la independencia de los presupuestos nacionales se opone a cualquier responsabilidad común o indirecta de los Estados miembros por las deudas de gobierno. BVerfGE. 129, 124 (181 y 182). Es más, reitera el TCF, la prohibición contenida en el art. 123 TFUE, que prohíbe la financiación de los Estados por el BCE, aparte de garantizar el principio de autonomía presupuestaria ligada al principio democrático de los Estados, es, además, 
y desde la perspectiva del derecho UE, también una de las reglas nucleares para la concepción de una unión monetaria como unión estable.

\section{EL PROGRAMA DE ADQUISICIÓN DE DEUDA PÚBLICA DEL BANCO CENTRAL EUROPEO Y EL PRINCIPIO DE RESPONSABILIDAD POR LA INTEGRACIÓN.}

a) El principio de responsabilidad por la integración y los deberes de acción y omisión por parte de los poderes públicos alemanes frente a actos ultra vires de la UE. La verificación de la existencia de un acto ultra vires, como acontece, a juicio del TCF, con la decisión del BCE sobre la adquisición de deuda pública, genera obligaciones tanto acción como de omisión para los órganos constitucionales del Estado alemán llamados a participar en el proceso de integración europea. Acciones y omisiones que son directamente invocables ante la jurisdicción constitucional [BVerfGE. 123, 267 (352, 389, 413), 126, 286 (307); 129, 124 (181), 132, 195 -Europäischer Stabilitätmechanismus - $(238,239)$ ]. Tales deberes de acción y de omisión son deducidos por el TCF de lo que ha denominado en su jurisprudencia el principio de responsabilidad por la integración [BVerfGE. 58, 1 (30 y 31)] que incide notablemente en la concepción del derecho y las funciones de los órganos constitucionales. Como se verá, los votos particulares presentados frente a la decisión mayoritaria de la Sala vienen a cuestionar fundamentalmente las consecuencias que se derivan por el TCF frente al programa de adquisición de deuda pública del BCE.

$\mathrm{Si}$, conforme a la jurisprudencia del TCF, durante el proceso de cesión competencial a la UE previsto en art. 23 de la Ley Fundamental, los órganos competentes han de garantizar que el Estado alemán retenga las facultades que definen formal y materialmente su soberanía, pesa sobre ellos la obligación positiva de velar porque los órganos de la UE se ajusten al programa de integración (entre otras, la BVerfGE. 75, 223 -Atomenwaffenstatonierung - , p. 173, BVerfGE. 89, 155, p. 102). Los citados deberes de acción y de omisión frente actos ultra vires indiscriminadamente impuestos a cualesquiera órganos que participen en el proceso de integración europeo, sea en el ámbito de las funciones de creación o de la aplicación de normas, lleva al TCF a entender en concreto respecto del programa de adquisición de deuda pública del BCE que: a) el Banco Central alemán debió no participar en la ejecución de la decisión del BCE y b) el Gobierno y el Parlamento federal debieron, en su caso, (1) promover una reforma de los tratados constitutivos para permitir legalidad de la decisión adoptada por el BCE y, en caso de no considerarlo oportuno, (2) adoptar todos los medios legales y políticos en favor de la derogación o la modificación de la decisión y (3) desplegar las medidas internas necesarias para minimizar los efectos de la decisión ultra vires del BCE.

En el marco de estas consideraciones, lo cierto es que la jurisprudencia del TCF dejó claro reiteradamente su papel defensor de la estatalidad y de la soberanía alemana frente al proceso de integración europeo [recientemente, BVerfGEE. 123, 
$267(352,389,413) ; 126,286$ (307), 129, 124 (180 у 181); 132, 195 (238 y 239)] - Sin embargo, como cabe apreciar de lo expuesto, parece evidente que el comentado principio de responsabilidad por la integración, nuevamente esgrimido en el supuesto de la decisión sobre el programa de adquisición de deuda pública del BCE, viene a convertir también a todos los órganos del Estado alemán en una suerte de potenciales defensores de la Constitución y de la soberanía del Estado alemán. Quizás debiera de reflexionarse si puede estimarse compatible con el principio democrático, el que el TCF aduce para calificar de ultra vires la decisión del BCE, la posibilidad de convertir al Gobierno y al Parlamento en órganos constitucionales garantes de la soberanía de la Constitución. Hasta tal punto, que la decisión aquí comentada del TCF reconoce que los grupos parlamentarios tienen interés legítimo en el planteamiento del conflicto interorgánico - como el que da lugar al casopara garantizar la eficacia del principio de responsabilidad por la integración y, en concreto, las obligaciones que de él se derivan para el Parlamento federal (BVerfGE. 123, 267 (337); 132, 195 (247). Los votos particulares presentados a la decisión mayoritaria de la Sala, como se verá, parecen avalar este planteamiento expuesto.

b) La relación entre el principio de responsabilidad por la integración y el derecho fundamental a participar en asuntos públicos. Conforme al razonamiento desarrollado por el TCF, el principio de responsabilidad por la integración no despliega sólo sus efectos en el ámbito del derecho de los órganos constitucionales, legitimando sólo a sus agentes ante la jurisdicción constitucional. Aquel principio, como se evidencia en la decisión comentada del TCF, irradia sus efectos también al ejercicio de los derechos fundamentales de la Ley Fundamental, en concreto al derecho fundamental a la participación política contemplado en su art. 38.1: «Los miembros del Bundestag alemán será elegidos en elecciones directas, libres, iguales y secretas». Es, concretamente, en el ámbito de este derecho fundamental donde la decisión del TCF sobre el programa de adquisición de deuda pública del BCE presenta su mayor innovación jurisprudencial.

La jurisprudencia constitucional sobre el proceso de integración había atribuido al derecho del art. 38,1 de la Ley Fundamental no sólo una perspectiva procedimental, aparando la elección de los representantes de los ciudadanos en elecciones periódicas. El TCF le confirió también una perspectiva sustantiva, reconociendo el derecho a sus titulares a: a) que la cesión del ejercicio de facultades de soberanía por parte del Parlamento federal a la UE conforme a lo previsto en el art. 23 de la Ley Fundamental, se lleve a cabo de acuerdo con los procedimientos formalmente dispuestos y b) que la voluntad del pueblo pueda incidir de manera eficaz sobre materias de contenido sustantivo [BVerfGE. 89, 155 (172)] y más en concreto, sobre las decisiones políticas fundamentales de la Ley Fundamental [BVerfGE. 123, 267 (330)]. Una cuestión esta última que se vincula al derecho de autodeterminación política de los ciudadanos, ligada al principio de la dignidad humana consagrado en el art. 1,1 de la Ley Fundamental [BVerfGE. 123, 267 (341)].

Complementando esta doctrina, el TCF entiende ahora que el derecho fundamental del art. 38,1 de la Ley Fundamental garantiza además la facultad de exigir 
de cualquier órgano llamado a crear o aplicar normas en el ámbito del derecho comunitario un comportamiento activo en defensa del núcleo formal y material de la soberanía del Estado alemán frente a actos ultra vires de la UE. La decisión del TCF sobre el programa de adquisición de deuda pública por parte del BCE trae causa precisamente en diferentes recursos de amparo presentados por la vulneración justamente del art. $38 \mathrm{GG}$, algo que genera importantes reservas para los dos magistrados firmantes de los votos particulares. El interesante debate que estos plantean se reproducen, en su esencia, a continuación.

\section{EL DEBATE PLANTEADO POR VOTOS PARTICULARES. ACTOS ULTRA VIRES, IDENTIDAD CONSTITUCIONAL Y DIVISIÓN DE PODERES}

Frente a las tesis expuestas en la decisión mayoritaria de la Sala, hasta aquí comentadas, se formularon dos votos particulares disidentes firmados por los magistrados Lübbe-Wolff y Gerhardt. Sus tesis introducen importantes dosis de criticismo sobre la doctrina emitida por el TCF en su decisión sobre el programa de adquisición de deuda pública del BCE. Y lo hacen, participando, sin embargo, de la tesis mayoritaria de la Sala proclive a atribuir a este órgano la competencia para el control del derecho de la UE cuando menoscabe la identidad del Estado alemán, concentrada en las materias sustraídas al cambio constitucional en el art. 79.3 de la Ley Fundamental. No obstante, discrepan en el hecho de que las omisiones del Parlamento y del Gobierno federal frente a la decisión ultra vires del BCE constituya una vulneración del derecho fundamental a la participación política que se reconoce en el art. 38 de la Ley Fundamental. Los votos particulares entienden que los recursos de amparo que dieron lugar al proceso debieron de ser desestimados. La magistrada Lübbe-Wolff, por su parte, extiende los mismos resultados al conflicto entre órganos constitucionales.

a) Los actos ultra vires de la UE como potencial lesión del derecho al voto del art. 38 de la Ley Fundamental. La extensión de la competencia de control del TCF. Los votos particulares presentados por los magistrados Lübbe-Wolff y Gerhardt apuntan que el TCF en la decisión del BCE sobre la adquisición de deuda pública extiende su competencia de control en el ámbito de la integración europea. Hasta el momento, el TCF había reconocido que el derecho fundamental a la participación política del art. 38 sólo quedaba lesionado cuando la ley de cesión competencial a la que alude el 23 desproveía al Estado alemán de competencias de peso sustantivo [BVerfGE. 89, 155 (171 y ss.)] o de las decisiones políticas fundamentales [BVerfGE. 123, 267 (330 y ss.)]. Como entienden los magistrados disidentes, ello generaba, para el TCF, una lesión del contenido esencial del derecho del art. 38, en tanto éste reconoce a sus titulares la facultad para poder influir de una manera eficaz sobre las decisiones de los órganos del Estado alemán. 
Para los magistrados disidentes, el TCF reconoce ahora que los actos ultra vires de la UE — no solo ya los del legislador alemán — también pueden suponer una vulneración del derecho del art. 38,1, reconduciendo a su contenido esencial la facultad de exigir que los órganos de la UE se acomoden a las competencias atribuidas por la ley aprobada por el Parlamento alemán. Vendría a ampararse así en el derecho fundamental a la participación política una suerte de derecho a la ejecución de la ley (allgemeiner Gesetzesvollziehungsanspruch), tal y como lo denomina el magistrado Gerhardt. Para los magistrados firmantes de los votos particulares, tras esta innovación jurisprudencial se encuentra, en el fondo, una alteración implícita del estándar de control del TCF, que va más allá de la que puede justificar coherentemente su acción, al lado de la propia del TJUE.

Efectivamente, para los magistrados disidentes el único ámbito constitucionalmente admisible para afirmar la facultad de control del TCF sobre el derecho comunitario en el contexto de una jurisprudencia que confiere la competencia primaria para el análisis de su validez y aplicabilidad al TJUE, es circunscribirla exclusivamente a la defensa de la identidad del Estado alemán. Es decir, a la protección de la eficacia de los principios reconocidos en el art. 79.3 de la Ley Fundamental, sustraídos a cualquier cambio constitucional. Para los magistrados Lübbe-Wolff y Gerhardt, el problema es que la tipología de actos de la UE a los que la decisión del TCF permite atribuir el carácter de ultra vires no tienen por qué coincidir necesariamente con el citado control de identidad de la soberanía del Estado alemán. Para los aludidos jueces, el TCF ha otorgado al requisito de que la infracción competencial deba de ser estructuralmente significativa [BVerfGE. 126, 286 (303 y 304)] una interpretación demasiado amplia.

Para Gerhardt, la decisión del TCF sobre el programa de adquisición de deuda pública del BCE evidencia tal peligro. La distinción de la que parte el TCF entre política monetaria y política, y sobre la que edifica su argumentación para concluir su naturaleza ultra vires es ficticia, ya que el contenido de ambas se entremezcla constantemente en la literalidad de los propios tratados constitutivos. En definitiva, si la jurisprudencia del TCF había dejado claro que los actos de la UE no están sujetos al control directo del TCF, sino sólo de manera indirecta en la medida en que afecten a su identidad constitucional [BVerfGE. 22, 293 (295 y ss.), 58, 1; 118, 79 (95); 129, 124 (175 y 176)], el TCF en esta decisión ha desnaturalizado de tal manera dicho control de identidad, que corre el riesgo de presentarse en un controlador ordinario de la validez y de la aplicación del derecho de la UE.

b) El control de las omisiones de los órganos del Estado y la división de poderes. Los votos particulares de los magistrados Lübbe-Wolff y Gerhardt apuntan que la decisión del TCF sobre el programa de adquisición de deuda pública aprobado por el BCE refleja otra relevante innovación jurisprudencial, en este caso, respecto de los actos potencialmente recurribles ante la jurisdicción constitucional. Como señalan los aludidos magistrados, el TCF había entendido hasta el momento que la falta de acción parlamentaria o gubernamental solo puede ser objeto de recurso cuando se puede esgrimir la existencia de un mandato constitucional explícito que 
predetermine el contenido y alcance del deber de actuación [BVerfGE. 129, 124 (176)]. Más en concreto, respecto al conflicto entre órganos constitucionales, el TCF ha mantenido que sólo cabe recurrir una omisión determinada, es decir, la ausencia de una acción específica que quepa reputar constitucionalmente impresdindible [BVerfGE. 131, 152 (190); 121, 135 (151); 118, 244 (257)].

La decisión del TCF sobre el programa de adquisición de deuda del BCE, según entienden, admite ahora que también las omisiones del Parlamento y del Gobierno federal respecto de un acto calificado como ultra vires de la UE pueden ser recurridas ante el TCF a través de un recurso de amparo por vulneración del derecho fundamental a la participación política que se reconoce en el art. 38,1 de la Ley Fundamental. De conformidad con ello, el derecho del art. 38,1 reconocería también la facultad de sus titulares a exigir de aquéllos órganos un comportamiento activo, sea en favor de la derogación de la decisión del BCE, de la limitación de sus efectos jurídicos dentro de Alemania o de la reforma de los tratados constitutivos para permitir la adecuación de aquélla a éstos. Posibilidades estas reconocidas en la decisión del TCF. El problema de tal doctrina no es en sí que contravenga su jurisprudencia anterior, que además reconoció que los actos positivos de cooperación intergubernamental en el seno de la UE no son objeto de control por parte del TCF [BVerfGE. 129, 124 (174)]. El auténtico problema para los que expresan opiniones disidentes a la Sala es que el TCF acaba vulnerando el principio de división de poderes.

Para los firmantes de los votos particulares, las medidas positivas que, a juicio del TCF, debe de adoptar el Parlamento o el Gobierno federal frente a un acto ultra vires de la UE entra dentro del margen de discrecionalidad política propio de tales órganos. No podrían considerarse, por tanto, jurídicamente exigibles, tampoco desde la perspectiva del derecho fundamental del art. 38 de la Ley Fundamental. Una prueba de ello, como se afirma en los votos particulares, es que la decisión del TCF sobre el programa de adquisición de deuda pública no despliega ninguna construcción teórica que sea capaz de justificar, por ejemplo, si además de la derogación de un acto ultra vires o la modificación de los tratados para permitir que el acto del BCE se ajuste al derecho originario existen otras medidas posibles. Tampoco si tales medidas han de entenderse como cumulativas o sucesivas. Y no la hay, simplemente porque, como se reitera en los votos particulares, tales conductas entran dentro del margen de apreciación política del Parlamento y del Gobierno federal, del debate parlamentario e intergubernamental. En consecuencia, los magistrados disidentes concluyen que el TCF ha interferido en las funciones propias de otros órganos, vulnerando el principio de división de poderes de la Ley Fundamental.

c) El principio de responsabilidad por la integración y la concepción de la constitución como un instrumento de integración. La exposición del razonamiento seguido por la voluntad mayoritaria de la Sala y las críticas, muchas de ellas coherentes, vertidas a aquélla en los votos particulares suscitan al lector la duda de si tras toda la problemática expuesta no subyace sino un debate de teoría del Estado y de la Constitución. El TCF a lo largo de su dilatada jurisprudencia se esforzó por construir un 
aparato dogmático como instrumento legitimador de las soluciones ofrecidas a los problemas planteados durante el proceso de integración europea. Este proceder, vinculado, como ha reflejado la literatura científica, a los presupuestos del constructivismo dogmático, se aprecia como en pocos lugares en la Sentencia Lisboa de 2009 en la que, con expresa citación de autores vinculados a la clásica teoría del Estado del siglo XIX, volvió a reafirmar sus convicciones teórico-formalistas vinculadas a los conceptos de soberanía y de estatalidad (véase TyRC, 32, p. 259 ss, con ulteriores referencias).

No obstante, el análisis de la propia Sentencia sobre el Tratado de Lisboa reflejó una clara combinación de categorías vinculadas a los presupuestos formalistas de la clásica teoría del Estado, con otros más propios de la materialización de la idea de Constitución. El intento de enumerar, por primera vez, las decisiones políticas fundamentales que predeterminaban la identidad del Estado alemán frente al proceso de la UE asumía un curioso paralelismo con una determinada etapa jurisprudencial del TCF que se vinculó al decisionismo para poder legitimar ciertas soluciones ofrecidas frente a determinados peligros contra el Estado alemán. La literatura científica alemana ha tratado de demostrar estos extremos (Lameyer, 1978). El deber impuesto por el TCF en la decisión sobre el programa del BCE de adquisición de deuda pública a todos los órganos constitucionales de implicarse activamente por la tutela de los principios que predeterminan la identidad del Estado tiene tantos puntos de conexión con la concepción de la Constitución como instrumento de integración, como el carácter no positivado de tales deberes con el derecho constitucional no escrito que tal concepto constitucional propugna (Smend, 1928).

Las objeciones constitucionales presentadas por los votos particulares contra la decisión mayoritaria de la Sala no reflejan más que las críticas que una concepción formalizada del principio democrático y de los derechos fundamentales presenta coherentemente a un ideal integracionista, que funcionaliza el derecho de los órganos constitucionales y los derechos individuales a una defensa activa de determinados valores, convirtiendo a aquéllos y a éstos en defensores políticos y jurídicos de la «Constitución». En ello parece convertir el TCF al Gobierno y al Parlamento federal, además de al Banco Central alemán, en defensores de la identidad constitucional frente a la decisión ultra vires del BCE, exigiendo de ellos un conjunto de comportamientos que, propiamente cabría definir como políticos, pero que resultan juridificados al trasluz de lo que parece ser una concepción de la Ley Fundamental como mecanismo de integración. La propia jurisprudencia del TCF ha permitido demostrar las consecuencias de este concreto modelo de Constitución aplicadas al funcionamiento del Estado federal, a fin de justificar la exigibilidad de determinados comportamientos política y jurídicamente debidos (BVerfGE. 12, 205). Como tuvo la ocasión de señalarse con anterioridad, habría que preguntarse si puede ser compatible con el principio democrático que órganos a los que se les reconoce la función de dirección política pueden convertirse también en defensores jurídicos de la Constitución, la lado de un Tribunal Constitucional, lo que parece conducir la 
interpretación del TCF. El tradicional debate sobre quién debe de ser el defensor de la Constitución en un Estado democrático parece volver de nuevo a la palestra.

$* * *$

TiTLE: Ultra vires acts of the European Union and the Right to political participation: the German Constitutional Court decision on acquisitation program public debt of the European Central Bank

Abstract: The January 14, 2014 the German Federal Constitutional Court ruled different appeals against the decision of the Council of the European Central Bank of 6 September 2012, authorizing the acquisition of certain States public debt in a context of severe economic crisis. The Court considers that such a decision has violated the constitutional identity of Germany and imposes the Government and Parliament on federal active duty to conduct to ensure respect for the constitutional identity. The breach of that duty by such bodies against the decision of the European Central Bank has violated the fundamental right of the appellants to political participation.

Resumen: El 14 de enero de 2014 el Tribunal Constitucional Federal alemán resolvió diferentes recursos presentados contra la Decisión del Consejo del Banco Central Europeo, de 6 de septiembre de 2012, que autorizaba la adquisición de deuda pública de ciertos Estados en un contexto de grave crisis económica. El Tribunal entiende que tal decisión ha vulnerado la identidad constitucional de Alemania e impone al Gobierno y al Parlamento federal el deber de un comportamiento activo para garantizar el respecto de la identidad constitucional. La inobservancia de dicho deber por parte de dichos órganos frente a la decisión del Banco Central Europeo ha vulnerado el derecho fundamental de los recurrentes a la participación política.

KeY wORDS: German Federal Constitutional Court, European Central Bank, constitutional identity, political participation.

Palabras Clave: Tribunal Constitucional Federal Alemán, Banco Central Europeo, identidad constitucional. participación política.

FECHA DE RECEPCIÓN: 10.05.2014 FeCHA DE ACEPTACIÓN: 30.07.2014 
